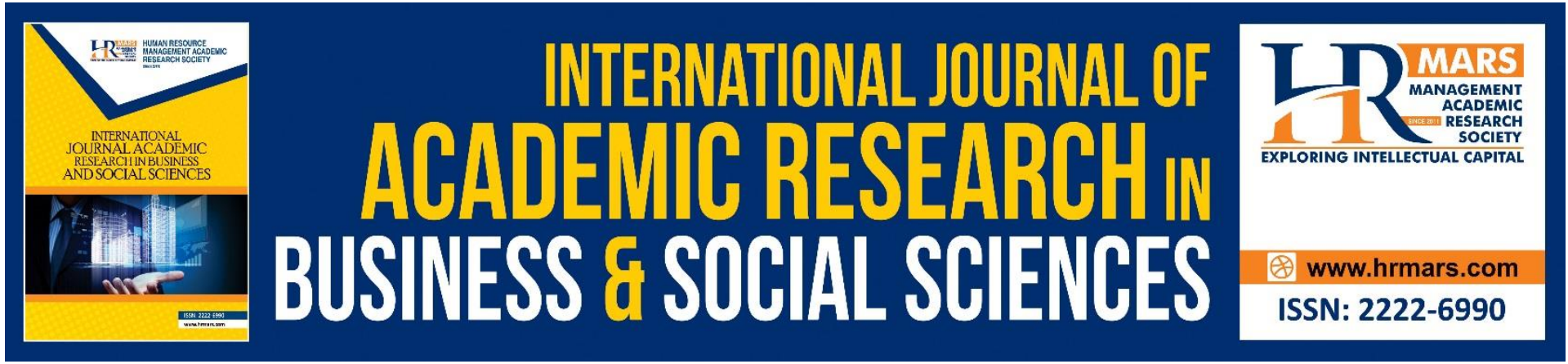

\title{
Academicians' Term of Experience on Sharing of Knowledge in Malaysian University
}

Norazila Mat, Jamsari Alias, Nur Atiqah Abdullah \& Nazri Muslim

To Link this Article: http://dx.doi.org/10.6007/IJARBSS/v11-i8/10773

DOI:10.6007/IJARBSS/v11-i8/10773

Received: 08 June 2021, Revised: 12 July 2021, Accepted: 30 July 2021

Published Online: 16 August 2021

In-Text Citation: (Mat et al., 2021)

To Cite this Article: Mat, N., Alias, J., Abdullah, N. A., \& Muslim, N. (2021). Academicians' Term of Experience on Sharing of Knowledge in Malaysian University. International Journal of Academic Research in Business and Social Sciences, 11(8), 829-844.

Copyright: (c) 2021 The Author(s)

Published by Human Resource Management Academic Research Society (www.hrmars.com)

This article is published under the Creative Commons Attribution (CC BY 4.0) license. Anyone may reproduce, distribute, translate and create derivative works of this article (for both commercial and non-commercial purposes), subject to full attribution to the original publication and authors. The full terms of this license may be seen at: http://creativecommons.org/licences/by/4.0/legalcode

Vol. 11, No. 8, 2021, Pg. 829 - 844

http://hrmars.com/index.php/pages/detail/IJARBSS

JOURNAL HOMEPAGE

Full Terms \& Conditions of access and use can be found at

http://hrmars.com/index.php/pages/detail/publication-ethics 


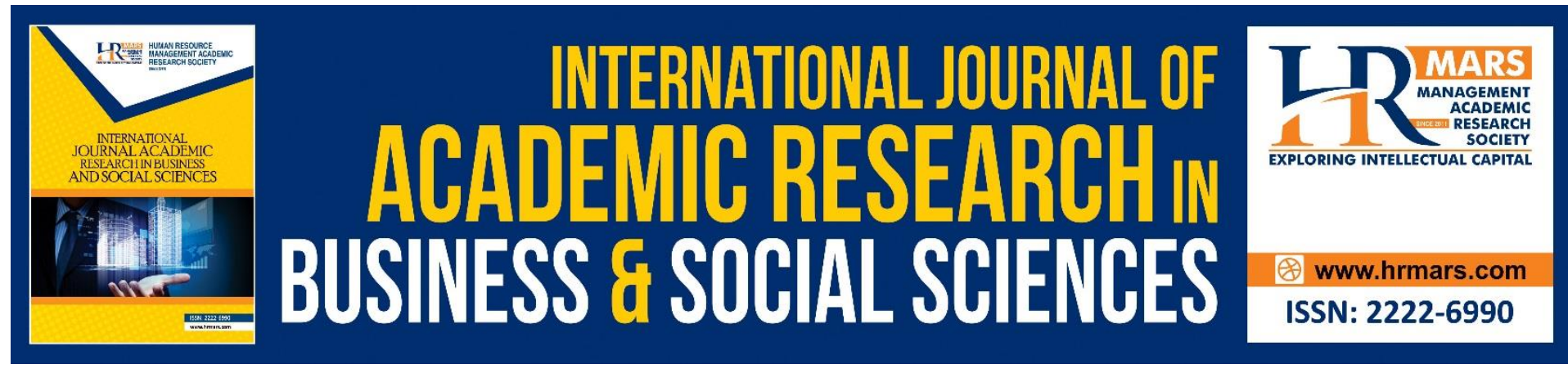

\title{
Academicians' Term of Experience on Sharing of Knowledge in Malaysian University
}

\section{Norazila Mat ${ }^{1}$, Jamsari Alias ${ }^{2}$, Nur Atiqah Abdullah ${ }^{1}$ \& Nazri Muslim²}

${ }^{1}$ Faculty of Economics and Management, Universiti Kebangsaan Malaysia, 43600 UKM Bangi, Selangor, ${ }^{2}$ Pusat Pengajian Citra Universiti, Universiti Kebangsaan Malaysia, 43600 UKM

Bangi, Selangor

Email:norazila@ukm.edu.my, jamsari@ukm.edu.my

\begin{abstract}
Knowledge sharing in Malaysian University is a vital driving force to enrich the pool of knowledge as well as offering fresh knowledge to students. However, extensive research in knowledge sharing between university academicians especially with different working experiences has been rather less discussed. This study aimed to identify the contrast between group of academicians with working experience of 10 years and below, with group of academicians with working experience of 11 years and above on three knowledge sharing factors; organizational factor, technological factor and individual factor. This study is conducted over a set of survey instrument among academicians in Universiti Kebangsaan Malaysia (UKM). Results from this study demonstrated that both groups of academicians approve that all factors are crucial especially knowledge self-efficacy under individual factors, but driving factors that are considered moderately important are organizational rewards under organizational factors and system quality under technical factors. These findings conclude that while there are no main concerns with individual factors of academicians in knowledge sharing, UKM's organization and technology in regards to knowledge sharing has rooms for improvement, specifically on organizational rewards and system quality.
\end{abstract}

Keywords: Knowledge Sharing, Organizational Factors, Technological Factors, Individual Factors, Academicians' Experience, Malaysian University.

\section{Introduction}

The rise of Malaysian university has provide an interesting landscape of knowledge sharing among academicians, as they are directly engaged in the knowledge business. Thus, it is critical for all academicians to understand knowledge sharing and what are the consequences of applying knowledge sharing towards their organizations. In order to serve as a pool of knowledge; where knowledge formation, distribution and learning are involved, academicians must comprehend the importance of upgrading their knowledge. Much have been pointed out on knowledge sharing, but less has been discoursed on the term of experiences among university academicians, especially regarding their number of years in work settings. Academicians in universities ought to have a good command of knowledge 
sharing, and in the process of sharing knowledge, and there are three main factors involved; namely organizational, technological, and individual factor (Lin, 2007).

Organizational factors are one of the factors in an organization that influence the process of knowledge sharing. In order to make knowledge become more influential in organizations, practising knowledge sharing is believed to be one of the many ways (Quinn et al., 1996). By having interaction and communication of individual co-workers, in project teams or between projects, the individual knowledge can be transferred into organizational knowledge and these knowledge sharing processes could give a hand in generating knowledge on an upper level (Nonaka et al, 1994). Correspondingly, through knowledge sharing, an organization can transmute the knowledge of individuals into organizational knowledge.

Knowledge sharing behavior of employees related to motivation has been regularly debated using self-determination theory (Ryan \& Deci, 2000). There are few renowned factors leading towards the success of knowledge sharing within individual factors such as trust, knowledge self-efficacy (Van Acker et al., 2014) and reciprocal benefits (Chennamaneni et al., 2012; Lin, 2007). Lai and Lee (2007) established that self-efficacy, job autonomy and trust directly induced the predisposition to share knowledge.

Since early days of knowledge management era the central viewpoints are around information technology and technology-driven (Davenport \& Prusak, 1998) while organizational culture, structure and information technology influenced the sharing capabilities among employees (Lee, 2001). Orlikowski (1992) specified two main elements in the concept of technology. Many have adopted virtual communities recently; in order to share data, cooperate in research and swap messages that offer impressions in knowledge sharing (Liao et al., 2013).

\section{Background of Knowledge Sharing}

Knowledge, outlined in this study as a combination of experience, values, contextual information and proficient understanding (Davenport \& Prusak, 1998), has been emphasized by many academicians and practitioners as the vital and inexpensive source for organizational achievement (Quinn et al., 1996; Albert \& Bradley, 1997). Organizations might not survive in Knowledge Era without appropriate strategy to handling and influencing value of their intellectual assets (Abell \& Oxbrow, 2001). This brings a large number of organizations, both tiny and big, turn to knowledge management approaches to manage and leverage their organizational knowledge in total (Davenport \& Prusak, 1998). Knowledge management can be defined as the performance of discovering, choosing, sharing evidence and expertise crucial for organizational activities (Gupta \& Govindarajan, 2000). As knowledge sharing is in the dealings between people, organization, and technology, organizations should contemplate aspects that embrace people, organization, and technlogy (Noor et al., 2014).

The study of knowledge sharing formerly is ruled by business organizations where their ultimate goal for knowledge sharing is revenue-motivated. However, the issue of knowledge sharing is equally important for a knowledge-based institution, such as a Higher learning institutions (HLI), where knowledge creation, dissemination and relevance are the main activity in the institution (Petrides \& Nodine, 2003). With the increased number of HLIs in Malaysia, there are a need for them to elevate their institution knowlegde in order to 
distinguish among themselve to serve as a pool of knowledge and are no longer just delivering knowledge to students. However, an all-inclusive research in the area of knowledge sharing between university faculty academicians especially in terms of academicians' working experience has been rather limited.

\section{Objective of Study}

This study is aimed:

a. to identify the comparison of perceptions of academicians with 10 years of experience and below and academicians with 11 years and above on organizational factors on knowledge sharing in HLIs.

b. to identify the comparison of perceptions of academicians with 10 years of experience and below and academicians with 11 years and above on technological factors on knowledge sharing in HLIs.

c. to identify the comparison of perceptions of academicians with 10 years of experience and below and academicians with 11 years and above on individual factors on knowledge sharing in HLIs.

\section{Literature Review}

Knowledge sharing is contemplated as one of the bedrock of knowledge management. According to the International Labour Organisation (ILO, 2006) knowledge sharing is "a process which starts by capturing and organizing knowledge and experience gained from others and proceeds to make the knowledge accessible to a larger audience - thus nurturing new linkages between interest group". Knowledge sharing also contains the transmission or dissemination of knowledge among individuals or groups as a basis for knowledge operation to create competitive advantage for the industry (Noor et al., 2014). Lee (2001) has defined knowledge sharing as "activities of transferring or disseminating knowledge from one person, group, or organization to another", while Van den Hooff \& de Ridder (2004) have further expounded on this view, adding that knowledge sharing is a process where individuals reciprocally interchange their knowledge and cooperatively produce new knowledge.

Knowledge sharing builds prospect to capitalize on organization ability to meet those needs and generates answers and proficiencies that provide a business with a competitive gain (Razmerita et al, 2016). Capturing, organizing, reusing, and transferring experience-based knowledge that lives within the organization and making that knowledge accessible to others in the business is knowledge sharing in an organization (Lin, 2007). A number of studies have revealed that knowledge sharing is indispensable because it permits organizations to improve innovation performance and ease away redundant learning efforts (Wasako \& Faraj, 2005).

An individual's intellectual capital progresses as he or she intermingles over time with others sharing the same drills and acquire the skills, knowledge, specialized discourse and norms of the practice where this understanding may be multiplied either through hands-on familiarities or through storylines told over times (Wasako \& Faraj, 2005). Working experience is the knowledge or skill gained from doing, seeing and feeling an action that uses physical or mental determination to do. According to Polanyi (1958), the capability to know is learned through a manner of understanding. Knowledge sharing is associated to the marathon of routine and competitiveness (Cabrera \& Cabrera, 2005). Knowledge from experiences gather by the social groups in inter and intra divisions, internal processes and even outside establishments is 
essential in knowledge sharing developments (Michailova \& Minbaeva, 2012). Knowledge sharing may also refer to individuals' knowledge, comprehensions and working experience that are related to present-day task (King, 2007) as knowledge sharing attempts to smoothen and improve job-related tacit knowledge amongst members of organization (Trivellas et al, 2015). Individuals that has better understand and experience in their skill are more likely be able to share their knowledge. Nevertheless, there must be explanations or factors that inspires them in applying knowledge sharing in jobs.

However, knowledge sharing is not an easy process due to the fact that knowledge in organizations is often held by individuals, units or groups (collective forms) spread all over the organization and sometimes across territorial frontiers (Argote \& Ingram, 2000). There are several challenges in knowledge management attempt like maintaining, locating and applying knowledge in organization. The major challenge in knowledge management is to enhance knowledge creation and sharing since the success or failure of knowledge management always depends on this (Wasako \& Faraj, 2005).

Furthermore, knowledge is recognized as being socially-complex since it is held by people and an individual relationship is needed in order to attain it and is considered as sticky and causally-ambiguous because it is implanted in a multifaceted network of formal and informal interactions, thus making it challenging for organizations to share it efficiently (Sanchez et al, 2013; Szulanski, 2000)

The key to productively handling knowledge is now being seen as reliant on the associations between individuals within the organization (Quinn et $L, 1996$ ). The literature recognizes the presence of different impacts on employee knowledge sharing undertakings, such as organizational, individual and technology factors (Chou et al., 2014).

Organizational knowledge resides on tacit and explicit knowledge and both are principal and harmonizing to each other and essential for knowledge creation (Nonaka et al., 2000). Explicit knowledge without tacit insight quickly loses its value since it can be easily copied by others so it needs to be shared with others so that new insights and learning will stimulate the knowledge. Tacit knowledge that cannot be codified and distributed throughout the organization also has the potential to be vanished when the person who holds it left the organization. Here, new knowledge or knowledge innovation is created through collaborations between tacit and explicit knowledge and not from either tacit or explicit knowledge unaccompanied (Nonaka et al., 2000). Therefore, it is imperative to manage and share both kinds of knowledge accordingly since different knowledge produces different benefit to organizations (Cabrera \& Cabrera, 2005). This vision brings a new perspective on the significance of different types of knowledge to different individuals, groups or units in organizations.

Management Support is an important organizational factor that could topmost towards better sharing of knowledge. Cabrera \& Cabrera (2005) suggest that staffing, job design, performance appraisal, compensation systems, managerial styles and drill all are related to management support that make up organizational factor for knowledge sharing. Furthermore, supports including participative decision making and confidence from the top management found to be confidently related to knowledge sharing (Park et al., 2004). 
Organizational Reward is another significant organizational factor that could lead towards heightened sharing of knowledge. Roca \& Gagne (2008) found out that need satisfaction was encouragingly related to sharing of knowledge while rewards could be made partially contingent on knowledge sharing actions as in merit pay, rewards based on joint performance are also likely to be effective in creating a sense of collaboration, ownership, and assurance among employees which include team-based rewards and organization wide incentives (profit sharing, gainsharing, and employee stock options) that would be mostly influential in enhancing knowledge sharing within teams and across work units in organizations.

Organizational culture or corporate culture refers to values, beliefs, and systems that may inspire or hinder knowledge creation and sharing within organizations (Bartol \& Srivastava, 2002). There is an exclusive culture that reflects the organization's identity along two magnitudes: visible and invisible for each organization (Bibi \& Ali, 2017). Develops over the time, the visible culture includes adopted values, mission and philosophy of the organization. As for the invisible part, it relates more to the standards and principles of the employees that guide their behaviour and actions (Razmerita et al., 2016). While organizational culture in sharing norms were found clearly related to knowledge sharing behavior in organizations it is also found that there is an affirmative link between opportunities to share which include organizational culture that embolden knowledge use and share (Chou et al., 2014). Bock \& Kim (2002) establish that anticipations to expand work relationships and to make a significant contribution to organizational performance were optimistically related to knowledge sharing mindsets and behaviors, and Park et al (2004) further found that a culture that boost teamwork, employee support, and autonomy strongly encourage and inspire knowledge sharing.

There are a number of individual factors leading towards the attainment of knowledge sharing, and among the individual factors are trust, knowledge self-efficacy and reciprocal benefits. Lin (2007) found that self-efficacy, job autonomy, and trust straightforwardly influenced the disposition to share knowledge.

Trust has several implications in social context, which principally could bring the meaning of a position where one party is eager to rely on the actions of another party that can grow and appraise expectations. Trust is also defined as the act of becoming accessible to people based on the good acknowledgement of the result of their action and regarded as the crucial point of every affiliation within the organizations (Noor et al, 2014). The level one party trusts another is a gauge of belief in the trustworthiness, fairness, or compassion of the other party that enriches knowledge sharing within organization and can boost the act of knowledge sharing (Hau et al., 2013).

Self-efficacy is the point of one's belief in one's own capacity to complete duties and reach their objectives that also influence employees' preparedness to share knowledge (Lin, 2007). While reciprocal is generally linked to bond in which an act of one party is met or defied with a corresponding act. In social psychology, reciprocity is a social rule that says people would repay, in the same manner, what another person has delivered for them (Cialdini et al., 2006). It is about giving back (reciprocate) the same conduct one has received earlier from the second party. 
System Infrastructure is an important organizational factor that could head towards healthier sharing of knowledge. According to Orlikowski (1992), the concept of technology comprises of two main foundations, that is scope and function. In terms of scope, there are two types of study (Ismail \& Yusof, 2010). One, the research that considers technology as 'hardware'; and two, the research that views technology as 'social technology'. In terms of function, early research foresees technology as an aim while other research focuses on technology as a product which contain people action on technology. The latest research refers technology as soft determining factor in which technology is considered as external factor that has impact but regulated by human and organization and always been the key variable in organizational theory (Orlikowski, 1992; Ismail \& Yusof, 2010).

While System Quality is highly expanded to complete different ways, including knowledge sharing, the purposes of information systems vary from entertainment, such as online games and social groups, to instrumental purposes, such as e-learning, e-commerce, and knowledge management systems. Until recently, many have adopted virtual groups to share data, join forces in research and swap messages that provide influences on knowledge sharing (Van Acker, 2014)

There are a number of factors leading towards the achievement of knowledge sharing, and so far researchers have highlighted that its motivation as a role of reciprocity issues, relationships with recipients and remunerations apart from of attitudes to share knowledge, working culture, inspiration to share, and opportunities to part (Ipe, 2003), while other researchers claim on tangile (monetary) rewards as well as intangible (non-monetary) rewards play equal important factors to encourage knolwedge sharing (McDermott \& O'Dell, 2001).

\section{Methodology}

This study is in the form of a descriptive study, on the perceptions of academicians regarding the term of experiences among university academicians, especially regarding their number of years in work settings. According to Wiersma (1995), this method is appropriate to gauge or assess the attitude, perception and achievement of a program. The descriptive form is also used at par with the requirement of the study to comprehend in its real phenomenon (Konting, 1990). Thus, a survey instrument is developed for this study based on the literatures selected. According to Tuckman (1999), a questionnaire is an operative way to gain evidence from the respondents. All questions are in positive form and the respondents were required to state their perceptions according to the Likert scale.

This study is conducted through a set of survey instrument among academicians in Universiti Kebangsaan Malaysia (UKM). The academicians are selected from 5 faculties, 2 faculties representing pure sciences group and another 3 faculties representing social sciences group in UKM. Thus, to regulate the number of respondents, The Sample Size Determination Table by Krejcie \& Morgan (1970) is adopted. The sample size for this study is 38 based on Krejcie \& Morgan (1970)'s Sample Size Determination.

In this study, an expert determines the validity of the questionnaire. Reliability refers to the stability and consistency in the instrument in measuring a particular concept. A popular test in measuring the consistency of a concept is the Cronbach Alpha. The reliability value of the 
Cronbach Alpha is between 0.0 and 1.0. According to (Konting, 1990), the Cronbach Alpha value more than 0.60 is often applied as the reliability index in a particular research. Thus, in this study, researcher has determined the Cronbach Alpha value that is more than 0.60 as the reliability value for every section of the questionnaire being tested. Next, to decide on the reliability value for the questionnaire given, researcher had carried out a pilot study.

The pilot study was done to recognize the weaknesses and the strength in the questionnaire provided. Thus, before the questionnaire was given, 10 academicians were selected to answer the questionnaire first. The outcome obtained shows that all 10 academicians understand the questions clearly. Then, by using the Statistical Package for the Social Science (SPSS) program version 21, it is confirmed that the Cronbach Alpha value for all the items of the questions obtained more than 0.6. Thus, the questionnaire constructed to carry out this study is reasoned applicable to be used.

\section{Results and Discussions}

\section{Findings and Discussions on Respondent Background}

The background of the respondents are as described in Table 1. The number of academicians from Pure Sciences comprises of 36.9 percent and Social Sciences academicians give a number of 63.1 percent. Majority of the respondents are from Senior Lecturers (44.7\%) with 65\% of all the respondents have been serving UKM for more than 11 years. 73.7 percent of the respondents are PhD holders who possess expertise and knowledge in their respective fileds, with 34.2 percent of them experiencing conducting research between 6 to 10 years.

From the demographic data obtained, the field of expertise among UKM academicians are generally divided into two; pure sciences and social sciences. For the position related to their post, they are categorized under the post of Professor, Associate Professor, Senior Lecturer and Lecturer. From the data, Senior Lecturers and Associate Professors make the majority with experience of work between 12 to 20 years of service with 6 to 10 years experiences in research. All the above indictors demonstrate to us that these academicians are in the process of climbing up their career development, which make truly important for them to share knowledge and create networking in their expertise to increase their research, publication and teaching. 
Table 1. Respondent Background

\begin{tabular}{|c|c|c|}
\hline$n=38$ & Numbers & Percentages \\
\hline \multicolumn{3}{|l|}{ Name of establishment } \\
\hline Faculty Science \& Technology & 2 & 5.3 \\
\hline Faculty Technology \& Information Science & 12 & 31.6 \\
\hline Faculty Economics \& Management & 5 & 13.2 \\
\hline Faculty Social Science \& Humanities & 14 & 36.8 \\
\hline Faculty Islamic Studies & 5 & 13.2 \\
\hline \multicolumn{3}{|l|}{ Position in this establishment } \\
\hline Professor & 3 & 7.9 \\
\hline Associate Professor & 9 & 23.7 \\
\hline Senior Lecturer & 17 & 44.7 \\
\hline Lecturer & 9 & 23.7 \\
\hline \multicolumn{3}{|l|}{ Years of working experience } \\
\hline $1-5$ & 8 & 21.1 \\
\hline $6-10$ & 5 & 13.2 \\
\hline $11-20$ & 18 & 47.4 \\
\hline $21 \&$ above & 7 & 18.4 \\
\hline \multicolumn{3}{|l|}{ Highest Educational Qualification } \\
\hline Doctoral Degree & 28 & 73.7 \\
\hline Master's Degree & 7 & 18.4 \\
\hline Bachelor Degree & 3 & 7.9 \\
\hline \multicolumn{3}{|l|}{ Years in Performing Research Work } \\
\hline 1 year $\&$ below & 2 & 5.3 \\
\hline $2-5$ years & 7 & 18.4 \\
\hline $6-10$ years & 13 & 34.2 \\
\hline $11-15$ years & 8 & 21.1 \\
\hline $16-20$ years & 4 & 10.5 \\
\hline $21-25$ years & 2 & 5.3 \\
\hline 26 years $\&$ above & 2 & 5.3 \\
\hline
\end{tabular}

Findings and Results on the factors related:

1. Organizational Factors (Top Management Support, Organizational Rewards and Organizational Culture)

Table 2. Organizational Factors

\begin{tabular}{|c|c|c|c|}
\hline & Low & Moderate & High \\
\hline Experience & & & \\
\hline 10 years and below & $0(0.0 \%)$ & $9(69.2 \%)$ & $4(30.8 \%)$ \\
\hline 11 years and above & $0(0.0 \%)$ & $13(52.0 \%)$ & $12(48.0 \%)$ \\
\hline
\end{tabular}

Table 2(a). Top Management Support

\begin{tabular}{|c|c|c|c|}
\hline & Low & Moderate & High \\
\hline Experience & & & \\
\hline 10 years and below & $0(0.0 \%)$ & $5(38.5 \%)$ & $8(61.5 \%)$ \\
\hline 11 years and above & $0(0.0 \%)$ & $3(12.0 \%)$ & $22(88.0 \%)$ \\
\hline
\end{tabular}


Table 2(b). Organizational Rewards

\begin{tabular}{|c|c|c|c|}
\hline & Low & Moderate & High \\
\hline Experience & & & \\
\hline 10 years and below & $3(23.1 \%)$ & $6(46.2 \%)$ & $4(30.8 \%)$ \\
\hline 11 years and above & $6(24.0 \%)$ & $14(56.0 \%)$ & $5(20.0 \%)$ \\
\hline
\end{tabular}

Table 2(c). Organizational Culture

\begin{tabular}{|c|c|c|c|}
\hline & Low & Moderate & High \\
\hline Experience & & & \\
\hline 10 years and below & $1(7.7 \%)$ & $4(30.8 \%)$ & $8(61.5 \%)$ \\
\hline 11 years and above & $0(0.0 \%)$ & $6(24.0 \%)$ & $19(76.0 \%)$ \\
\hline
\end{tabular}

Table 2 describes on the Organizational Factors in knowledge sharing applications among the academician in UKM. It can be seen from the table, both academicians with 10 years of experience and below (69.2\%) and with 11 years of experience and above (52.0\%), moderately agreed in organizational factors in knowledge sharing application among academicians.

Table 2(a), 2(b) and 2(c) above describe on the top management support, organizational rewards and organizational culture aspects under Organizational Factors, respectively, in knowledge sharing applications among academicians. From the data, both academicians with 10 years of experience and below (61.5\%) and academicians with 11 years of experience and above (88.0\%) agreed that top management support have a high influence on knowledge sharing between academicians. However, academicians with 10 years of experience and below (23.1\%) and academicians with 11 years of experience and above (24.0\%) hardly believe that organizational rewards are not a major factor in knowledge sharing in UKM, but organizational culture is highly considered as a driving factor of knowledge sharing as believed by academicians with 10 years of experience and below (61.5\%) and academicians with 11 years of experience and above (76.0\%).

These findings in general show that both academicians with 10 years of experience and below and with 11 years of experience and above moderately agree that top management support and organizational culture are important factors in knowledge sharing but it is a different case with organizational rewards. It is an indicator that regardless of experience, top management in UKM is very much encouraging in knowledge sharing among academicians, provides most of the necessary facilities required, and is satisfied with the sharing practices (Mat et al, 2016). It is also the same with the organizational culture in regards to academician's experience, which reflects top management's encouragements for academicians to involve in conferences and stresses the importance of knowledge sharing among academicians. However, lack of belief in organizational rewards as an important factor in knowledge sharing among academicians shows that academicians regardless of experience lack of material rewards such as job promotions and receiving higher monetary bonus, but ample and satisfied with the non-material rewards such as acknowledgements and positive reputations. 
2. Technological Factor (System Infrastructure and System Quality)

Table 3: Technological Factor

\begin{tabular}{|l|c|c|c|}
\hline & Low & Moderate & \multicolumn{1}{c|}{ High } \\
\hline Experience & & & \\
\hline 10 years and below & $1(7.7 \%)$ & $5(38.5 \%)$ & $7(53.8 \%)$ \\
\hline 11 years and above & $1(4.0 \%)$ & $8(32.0 \%)$ & $16(64.0 \%)$ \\
\hline
\end{tabular}

Table 3(a): System Infrastructure

\begin{tabular}{|l|c|c|c|}
\hline & Low & Moderate & High \\
\hline Experience & & & \\
\hline 10 years and below & $2(15.4 \%)$ & $4(30.8 \%)$ & $7(53.8 \%)$ \\
\hline 11 years and above & $1(4.0 \%)$ & $6(24.0 \%)$ & $18(72.0 \%)$ \\
\hline
\end{tabular}

Table 3(b): System Quality

\begin{tabular}{|l|c|c|c|}
\hline & Low & Moderate & High \\
\hline Experience & & & \\
\hline 10 years and below & $1(7.7 \%)$ & $7(53.8 \%)$ & $5(38.5 \%)$ \\
\hline 11 years and above & $1(4.0 \%)$ & $10(40.0 \%)$ & $14(56.0 \%)$ \\
\hline
\end{tabular}

Table 3 describes on the Technological Factors in knowledge sharing applications among the academicians. As shown, both academicians with 10 years of experience and below $(53.8 \%)$ and with 11 years of experience and above (64.0\%), strongly agreed in Technological Factors in knowledge sharing application among academicians in UKM.

Table 3(a) and 3(b) above shows the system infrastructure and system quality aspects under Technological Factors, respectively, in knowledge sharing applications among academicians. From the data, majority of academicians with 11 years of experience and above (72.0\%) highly believed that system infrastructure is an important factor in knowledge sharing while $15.4 \%$ of academicians with 10 years of experience and below think otherwise. However, just over half of academicians with 11 years of experience and above (56.0\%) believed that system quality is major factor in knowledge sharing but $53.8 \%$ of academicians with 10 years of experience and below moderately believe so.

These findings in general show us that the system infrastructure in UKM for knowledge sharing is slightly high where there are supportive systems available such as an online system that helps academicians of both experience groups to engage in learning and teaching amongst each other. Moderate belief in system quality from academicians with different working experience as a major factor in knowledge sharing shows that it can still be improved in terms of its relevance, accurateness, up to date, dependency and easier access. The applications developed in the system infrastructure are significant in making knowledge sharing process a success. At the same time, UKM need to ensure that the systems developed are more dependable and easy to access to all academicians (Mat et al, 2017). 
3. Individual Factors (Trust, Knowledge Self-Efficacy and Reciprocal Benefits)

Table 4: Individual Factors

\begin{tabular}{|l|c|c|c|}
\hline & Low & Moderate & \multicolumn{1}{c|}{ High } \\
\hline Experience & & & \\
\hline 10 years and below & $0(0.0 \%)$ & $5(38.5 \%)$ & $8(61.5 \%)$ \\
\hline 11 years and above & $0(0.0 \%)$ & $5(20.0 \%)$ & $20(80.0 \%)$ \\
\hline
\end{tabular}

Table 4(a): Trust

\begin{tabular}{|l|c|c|c|}
\hline & Low & Moderate & High \\
\hline Experience & & & \\
\hline 10 years and below & $0(0.0 \%)$ & $5(38.5 \%)$ & $8(61.5 \%)$ \\
\hline 11 years and above & $0(0.0 \%)$ & $7(28.0 \%)$ & $18(72.0 \%)$ \\
\hline
\end{tabular}

Table 4(b): Knowledge Self-Efficacy

\begin{tabular}{|l|c|c|c|}
\hline & Low & Moderate & High \\
\hline Experience & & & \\
\hline 10 years and below & $0(0.0 \%)$ & $4(30.8 \%)$ & $9(69.2 \%)$ \\
\hline 11 years and above & $0(0.0 \%)$ & $4(16.0 \%)$ & $21(84.0 \%)$ \\
\hline
\end{tabular}

Table 4(c): Reciprocal Benefits

\begin{tabular}{|l|c|c|c|}
\hline & Low & Moderate & High \\
\hline Experience & & & \\
\hline 10 years and below & $0(0.0)$ & $4(30.8 \%)$ & $9(69.2 \%)$ \\
\hline 11 years and above & $0(0.0)$ & $6(24.0 \%)$ & $19(76.0 \%)$ \\
\hline
\end{tabular}

Table 4 describes on the Individual Factors in knowledge sharing applications among the academician in UKM. As shown, both academicians with 10 years of experience and below (61.5\%) and with 11 years of experience and above (80.0\%), strongly agreed in Individual Factors in knowledge sharing application among academicians.

Table 4(a), 4(b) and 4(c) above describe on the trust, knowledge self-efficacy and reciprocal benefits aspects under Individual Factors, respectively, in knowledge sharing applications among academicians in UKM. Academicians with 10 years of experience and below (61.5\%) and academicians with 11 years of experience and above (72.0\%) believed that trust is an important factor in knowledge sharing while academicians with 10 years of experience and below (69.2\%) and academicians with 11 years of experience and above (84.0\%) highly agree that knowledge self-efficacy is also a major factor in knowledge sharing. As for reciprocal benefits of knowledge sharing, academicians with 10 years of experience and below (69.2\%) and academicians with 11 years of experience and above (76.0\%) highly believed that it is an influencing factor in knowledge sharing as agreed in (Mat et al., 2019).

The results above shows that knowledge sharing practices among academicians regardless of working experience in UKM are strongly related with the individual factors of "Trust", "Knowledge Self-efficacy" and "Reciprocal Benefit". Thus, every academician should possess 
all the three aspects of "Trust", "Knowledge Self-efficacy" and "Reciprocal Benefit"; to improve knowledge sharing practice (Mat et al., 2016b).

\section{Conclusions}

From the data explained, this study in general demonstrates that both academicians with 11 years of experience and above and academicians with 10 years of experience and below, strongly believe that Individual Factors are the main factors in knowledge sharing applications among academicians. Both groups of academician also intensely believe in knowledge selfefficacy aspect under the Individual Factors in knowledge sharing applications among academicians. They are also in consensus when it comes to Technological Factor and believed that it is an important aspect in knowledge sharing among academicians, but moderate belief in the system quality from both academicians of different working experience reflects on the room for improvements that can still be made. As for Organizational Factors in knowledge sharing, both group of academicians in this study believed that top management support and organizational culture are critical factors in knowledge sharing but it is a different case with organizational rewards. Their moderate belief in organizational rewards displays that academician regardless of experience lack of material rewards such as job promotions and receiving higher monetary bonuses.

Thus, this study contributes towards better understanding on the theoretical aspect of how different factors affecting knowledge sharing, namely the individual factor, technological factor as well as organizational factor responds towards the academicians' term of experience in term of their years of involvement. In term of contextual contribution, when comparing these different group of academicians based on their working experiences, the results has shown that regardless of their working experiences, their unanimity seems to match on each factors. This brings the role that the factors which perceived moderate in knowledge sharing applications such as system quality and organizational rewards spread through both group of academicians evenly. Therefore, in order for knowledge sharing applications to run smoothly, the university has to improve their system quality, organizational rewards and maintain other factors at its current level.

\section{Acknowledgement}

This study is sponsored by research grant from the Universiti Kebangsaan Malaysia (UKM); under Research Code EP-2019-034.

\section{References}

Abell, N., Oxbrow, S. (2001) Competing with knowledge: the information professional in the knowledge management age. London: Library Association Publishing.

Albert, S., Bradley, K. (1997) Managing knowledge: Experts, agencies and organizations. Cambrige University Press.

Argote, L., Ingram, P. (2000) Knowledge transfer: A basis for competitive advantage in firms, Organizational Behavior and Human Decision Processes, Vol. 82, No. 1, pp. 150-169.

Bartol, K. M., Srivastava, A. (2002) Encouraging knowledge sharing: The role of organizational reward systems, Journal of Leadership \& Organizational Studies, Vol. 9, No. 1, pp. 6476.

Bibi, S., Ali, A. (2017) Knowledge sharing behavior of academics in higher education, Journal of Applied Research in Higher Education, Vol. 9, No. 4, pp. 550-564. 
Bock, G. W., Kim, Y. G. (2002) Breaking the Myths of Rewards: An Exploratory Study of Attitudes about Knowledge Sharing, Information Resources about Management Journal, Vol. 15, No. 22, pp. 14-21.

Cabrera, E. F. (2005) A. Cabrera. Fostering knowledge sharing through people management practices, The International Journal of Human Resource Management, Vol. 16, No. 5, pp. 720-735.

Chennamaneni, A., Teng, J. T., Raja, M. (2012) A unified model of knowledge sharing behaviors theoretical development and empirical test, Behavior and Information Technology. Vol 31, No. 11, pp 23-31.

Chou, H. W., Lin, Y. H., Lu, H. H., Chang, S. B. (2014) Knowledge sharing and ERP system usage in post-implementation stage, Computers in Human Behavior, Vol. 33, pp. 16-22.

Cialdini, R. B., Demaine, L. J., Sagarin, B. J., Barrett, D. W., Rhoads, K., Winter, P. L. (2006) Managing social norms for persuasive impact. Social Influence, Vol. 1, No. 1, pp. 3-15.

Davenport, T. H., Prusak, L. (1998) Working knowledge: how organizations manage what they know. Harvard Business Press.

Gupta, A. K., Govindarajan, V. (2000) Knowledge flows within multinational corporations. Strategic Management Journal, Vol. 21, No 4, pp. 473-496.

Hau, Y. S., Kim, B., Lee, H., Kim, Y. G. (2013) The effects of individual motivations and social capital on employees' tacit and explicit knowledge sharing intentions. International Journal of Information Management, Vol. 33, No. 2, pp. 356-366.

International Labour Organisation. (2006) Knowledge Sharing: Gender equality in the world of work

Ipe, M. (2003) Knowledge sharing in organizations: a conceptual framework, Human Resource Development Review, Vol. 2, No. 4, pp. 337-59.

Ismail, M. B., Yusof, Z. M. (2010) The impact of individual factors on knowledge sharing quality, Journal of Organizational Knowledge Management, Vol. 13, pp. 1-12.

King, W. (2007) A research agenda for the relationships between culture and knowledge management, Knowledge and Process Management, Vol. 14, No. 3, pp. 226-236.

Konting, M. M. (1990) Kaedah Penyelidikan Pendidikan. Kuala Lumpur: Dewan Bahasa dan Pustaka.

Krejcie, R. V., Morgan, D. W. (1970) Determining sample size for research activities, Educational and Psychology Measurement, Vol. 30, No 3.

Lai, M. F., Lee, G. G. (2007) Relationship of organizational culture towards knowledge activities, Business Process Management Journal, Vol. 13, No. 2, pp. 306-322.

Lee, N. J. (2001) The impact of knowledge sharing, organizational capability and partnership quality on IS outsourcing success. Information and Management, Vol 38, No 5, pp. 323335.

Liao, C., Hsu, C P. L. (2013) Exploring knowledge sharing in virtual communities. Online Information Review.

Lin, H. F. (2007) Effects of extrinsic and intrinsic motivation on employee knowledge sharing intentions, Journal of Information Science, Vol. 33, No. 2, pp. 135-149.

Mat, N., Alias, J., Abdullah, N. A., Yazid, Z., Muslim, N. (2019) Knowledge Sharing Factors: Perception between Junior and Senior Academicians in Malaysian University, International Journal of Scientific and Technology Research, Vol 8, No 12, 1255-1263.

Mat, N., Alias, J., Muslim, N. (2016) The impacts of organizational factors on knowledge sharing in higher learning instituitions (HLIs): Case at Universiti Kebangsaan Malaysia (UKM), Mediterranean Journal of Social Sciences, Vol. 7, No. 6, pp. 181-187. 
Mat, N., Alias, J., Muslim, N. (2016b). Individual factors on knowledge sharing among academicians at Universiti Kebangsaan Malaysia (UKM), Social Sciences (Pakistan), Vol. 11, No. 19, pp. 4771-4775.

Mat, N., Alias, J., Muslim, N. (2017) Perceptions of Universiti Kebangsaan Malaysia (UKM) Academicians on the Impacts of Technological Factors on Knowledge Sharing, International Business Management, Vol. 100, No. 1, pp. 183-188.

McDermott, R., O'Dell, C. (2001) Overcoming Culture Barriers to Sharing Knowledge, Journal of Knowledge Management, Vol 5, No. 1, 76-85.

Michailova, S., Minbaeva, D. B. (2012) Organizational values and knowledge sharing in multinational corporations: The Danisco case, International Business Review, Vol. 21, No. 1, pp. 59-70.

Nonaka, I., Byosiere, P., Borucki, B., Konno, N. (1994) Organizational knowledge creation theory: A first comprehensive test, International Business Review. Vol. 3, No. 4, pp. 337-351.

Nonaka, I., Toyama, R., Konno, N. (2000) SECl, Ba and Leadership: A Unified Model of Dynamic Knowledge Creation. Long Range Planning.

Noor, A. D., Hashim, H. S., Ali, N. (2014) Factors Influencing Knowledge Sharing Organizations: A Literature Review, International Journal of Science and Research, Vol. 3, No. 9, pp 1314-1317.

Orlikowski, W. J. (1992) The Duality of Technology: Rethinking the Concept of Technology in Organizations. Organization Science.

Park, H., Ribeire, V., Schulte, W. D. (2004) Critical Attributes of Organizational Culture that Promote Knowledge Management Technology Implementation Success, Journal of Knowledge Management, Vol. 8, No. 3, pp. 106-117.

Petrides, L., Nodine, T. (2003) KM in Education: Defining the Landscape, Institute for the Study of Knowledge Management in Education, Half Moon Bay, CA.

Polanyi, M. (1958) Personal Knowledge: Towards a Post-Critical Philosophy. University of Chicago Press, Chicago.

Quinn, J. B., Anderson, P., Finkelstein, S. (1996) Managing professional intellect: making the most of the best. Harvard Business Review.

Razmerita, K., Kirchner, K., Nielsen, P. (2016). What factors influence knowledge sharing in organizations? A social dilemma perspective of social media communication, Journal of knowledge Management, Vol. 20, No. 6, pp. 1225-1246.

Roca, J. C., Gagne, M. (2008) Understanding E-Learning Continuance Intention in the Workplace: A Self-Determination Theory Perspective, Computers in Human Behavior, Vol. 24, No. 4, pp. 1596-1604.

Ryan, R. M., Deci, E. L. (2000) Intrinsic and Extrinsic Motivations: Classic Definitions and New Directions. Contemporary Educational Psychology, Vol 25, No 1, pp. 54-67.

Sánchez, J. H., Sánchez, Y. H., Collado-Ruiz, D., Cebrián-Tarrasón, D. (2013) Knowledge Creating and Sharing Corporate Culture Framework, Procedia - Social and Behavioral Sciences, pp 25-33.

Szulanski, G. (2000) The process of knowledge transfer: A diachronic analysis of stickiness, Organizational Behavior and Human Decision Processes, Vol. 82, No. 1, pp. 9-27, 2000.

Trivellas, P., Akrivouli, Z., Tsifora, E., Tsoutsa P. (2015) The Impact of Knowledge Sharing Culture on Job Satisfaction in Accounting Firms. The Mediating Effect of General Competencies, Procedia Economics and Finance, Vol. 19, pp. 238-247. 
Tuckman, B. W. (1999) Conducting Educational Research. Fort Worth: Harcourt Brace College Publishers.

Van Acker, F., Vermeulen, M., Kreijns, K., Lutgerink, J., Van Buuren, H. (2014) The role of knowledge sharing self-efficacy in sharing Open Educational Resources. Computers in Human Behavior. Vol. 39, pp. 136-144.

Van Den Hooff, B., De Ridder, J. A. (2004) Knowledge sharing in context: the influence of organizational commitment, communication climate and CMC use on knowledge sharing, Journal of Knowledge Management, Vol. 8, No. 6, pp. 117-130.

Wasako, M., Faraj, S. (2005) Why Should I Share? Examining Social Capital and Knowledge Contribution in Electronic Newtworks Practice, MIS Quarterly, Vol. 29, No. 1, pp. 3557.

Wiersma, W. (1995) Research Methods in Education: An Introduction, Allyn and Bacon, Boston, MA. 